Journal of Research in Interprofessional

Practice and

Education

Vol. 9.2

2019

a. Université de Montréal

\title{
Interprofessional Collaborative Practice and Law: A Reflective Analysis of 14 Regulation Structures
}

\author{
Marie-Andrée Girard MD FRCPC LLD(c) ${ }^{a}$
}

\begin{abstract}
Background: Interprofessional collaboration (IPC) is a key element of an efficient healthcare system. Are healthcare systems structured to facilitate IPC?

Methods and findings: Fourteen jurisdictions were chosen and researched using legal and social sciences databases. Generally, there was a lack of understanding of the legal principles in literature on policy and IPC. That aside, every jurisdiction had acts and regulation specific to health professions. There were numerous pathways to professional regulation and no clear consensus. Regarding IPC presence in legal text, there were two main integration pathways: professional-based and organization-based approaches.

Conclusion: Although the practice of IPC is important, its presence in regulation is still discrete. If the aim is to strengthen IPC, there must be more socio-legal research to properly address and inform policymakers.

Keywords: Health regulation; Professional regulation; Interprofessional practice; Interprofessional collaboration
\end{abstract}

\section{Journal of Research in Interprofessional Practice and Education (JRIPE) \\ Vol. 9.2 \\ (C) 2019}

doi: 10.22230/jripe.2019

v9n2a285

Corresponding author: Marie-Andrée Girard. Email: marie-andree .girard1@umontreal.ca

\section{Introduction}

Interprofessional collaboration (IPC) is now accepted as a key element of an efficient healthcare system. In that context, most policymakers and health professionals strive to develop and implement such a practice. Yet, they encounter resistance due to ingrained culture and structures. To allow IPC to flourish, researchers must put forward the importance of changing professional culture from its historically siloed mono-professional characteristics and call into question the dominant position held by the physician in the overall healthcare structure $[1,2]$. This is not conducive to an equal relationship among health professionals, with a horizontal leadership [3,4]. What social science literature tends to overlook is that these social constructs and paradigms gave birth to legal notions such as the scope of practice and the definitions of professional acts. These regulations crystallize professional hierarchy and medicine dominance $[1,5]$.

Siloed thinking and hierarchy are not only present in the culture and micro-level working relationships; they are embedded in the regulations structuring the healthcare system itself. As researchers have already underlined, such a situation creates a dynamic based more on professional practice turf than on a care continuum $[3,6,7,8]$. To promote IPC and tackle this dynamic, stakeholders and policymakers, 
2

IPC and Law:

Analysis

Girard

Journal of Research in Interprofessional Practice and Education

Vol. 9.2

2019 while acknowledging the culture, have to address the siloed and linear structure that has arisen from an inherited healthcare profession-based structure. The actual conundrum is that stakeholders and policymakers have to challenge this structure while knowing very little about healthcare structural policy and the laws determining it [9].

Yet, one can argue that most developed countries are burgeoning with IPC and interprofessional education (IPE) initiatives without introducing broad legislative changes. The main issue is that these initiatives are often linked to a pilot project or specific funding, which hinders their stability [10]. This is why it is important to study the law. Health law and health policies offer a hint about the potential of IPC. In fact, the law is the product of how political and social culture interact in one country [11]. Regulation is then the expression of the will of either the government or the professionals themselves. Because of this performative nature, the legal presence of IPC is a good clue that the regulators want to implement further collaboration or interprofessional practice in a specific healthcare system $[11,12,13]$. When the will is strong enough to percolate into legal texts, IPC will be part of healthcare's culture.

\section{Aim}

The objective of this article is to perform an analysis of the impact of interprofessional regulations and contribute to the creation of a research agenda on global IPC policy and regulation. The article comprises a descriptive study of 14 jurisdictions in 10 countries, focusing on legal texts in search of facilitators of or references to IPC. The aim is not to venture into the realm of comparative law but to present general principles embedded in healthcare regulation concerning IPC from specific developed countries (14 states and provinces in total). This description of the current legal aspect aims to foster a discussion on IPC evolution and IPC legal structure support, especially when it comes to comparing initiatives from different countries and states.

\section{Process and method}

Since specific literature on the IPC global legal structure is scarce $[6,7,8]$, a broad aggregative narrative review method was first used to identify legally based concepts in an international perspective [14]. This type of narrative review was chosen because it enables both legal policy analysis and social science literature analysis, facilitating dialogue between the two literatures [15]. To maximize the scope of the study, 10 countries from different historic legal traditions were identified. Based on those legal jurisdictions, a query of the legal literature was made on HeinOnline $e^{\text {tw }}$ and health organization or legislation websites using combinations of the following keywords: "health professions," "interprofessional care," "collaborative practice," "professional regulation," and "healthcare regulation." Subsequently, to complete the exercise, the same Boolean research terms were used in Google Scholar ${ }^{\mathrm{rn}}$ and PubMed $^{\mathrm{Tm}}$. Inclusion criteria were articles published in the last 20 years, in English or French. Exclusion criteria were articles not containing legal, regulation, or policy reference; not focusing on factors influencing IPC; or not related to the chosen jurisdictions. Finally, all texts not containing original material, either published as book chapters or non-governmental reports, were excluded (see Figure 1). 
3

IPC and Law:

Analysis

Girard
SOCIO-EMPIRICAL LITERATURE RESEARCH

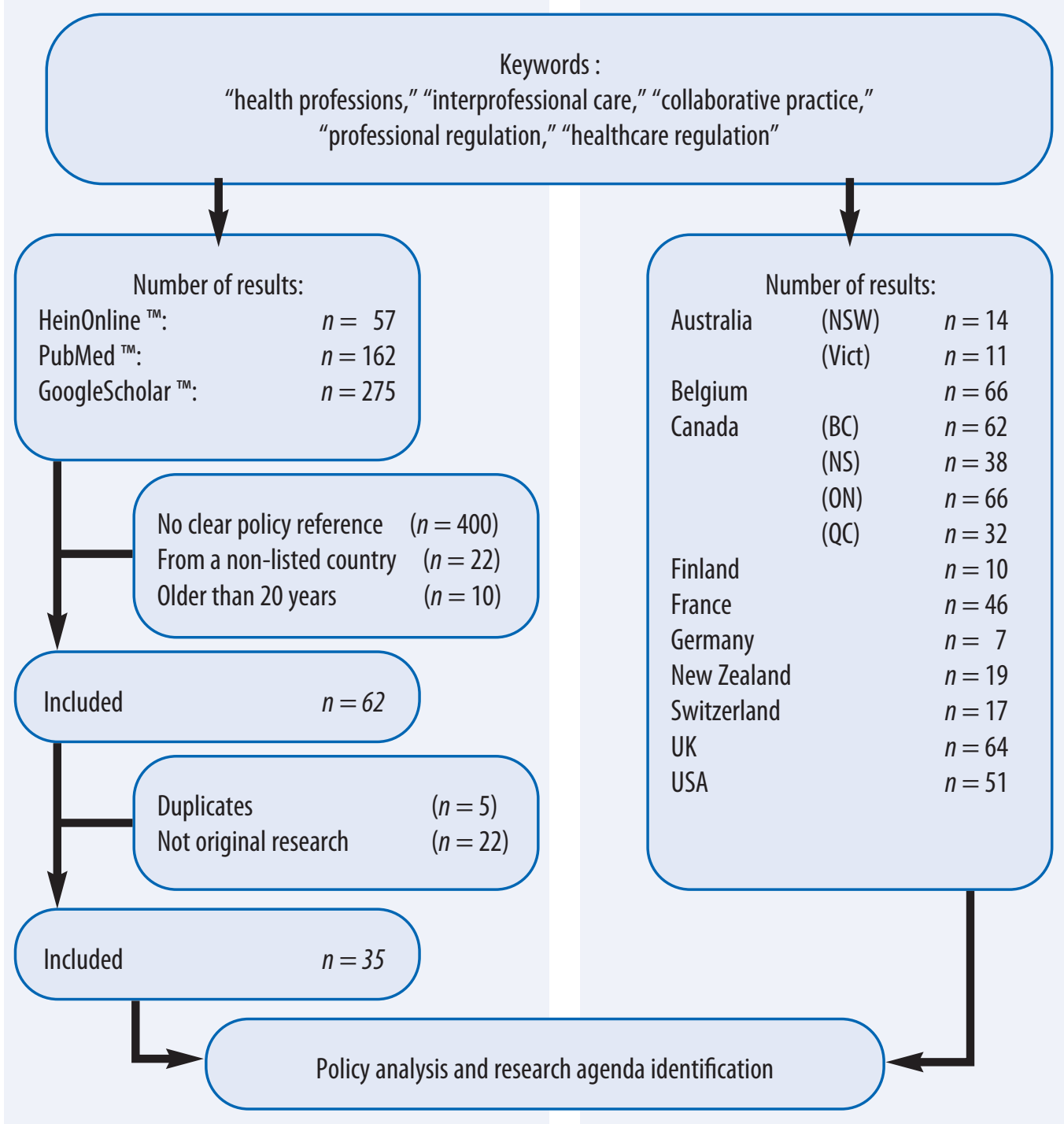

Figure 1: Method and process

\section{Results}

Fourteen states and provinces were chosen and researched: Canada (four provinces: British Columbia, Nova Scotia, Ontario, and Quebec), the United States of America, France, Belgium, Switzerland, United Kingdom, Australia (two states: New South Wales and the State of Victoria), New Zealand, Finland, Germany (see Figure 1). These countries were chosen based on data access, the availability of translated legal texts (English or French), and the existence of a searchable database. As stated earlier, the polymorphism of legal structures demands some caution from a strictly legal point of view: comparing those texts is hard since every law or act exists in a complex system of acts and decrees reflecting a specific society. Nonetheless, the results are separated into three themes: what is common, what is different, and what is the legal presence of IPC (see Table 1 for complete results). 
4

IPC and Law: Analysis

Girard

Journal of Research in Interprofessional Practice and Education

Vol. 9.2

2019
Table 1: Legal review results

\begin{tabular}{|c|c|c|c|c|c|}
\hline & $\begin{array}{c}\text { Philosophy } \\
\text { of } \\
\text { regulation }\end{array}$ & $\begin{array}{c}\text { Type of } \\
\text { professional } \\
\text { regulation }\end{array}$ & $\begin{array}{l}\text { Healthcare } \\
\text { professional } \\
\text { regulation }\end{array}$ & IPC integration \\
\hline \multirow{2}{*}{ 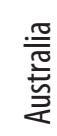 } & New South Wales & co & Umbrella & Status + Delivery role & Code of conduct based \\
\hline & Victoria & CO & Umbrella & Status + Delivery role & Code of conduct based \\
\hline \multicolumn{2}{|c|}{ Belgium } & explicit & Umbrella & Status + Delivery role & Healthcare-system based \\
\hline \multirow{4}{*}{ 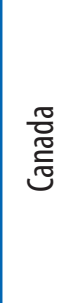 } & British Columbia & co & Umbrella & Status + Delivery role & Profession-regulators based \\
\hline & Ontario & co & Umbrella & Status + Delivery role & Profession-regulators based \\
\hline & Quebec & co & Umbrella & Status + Delivery role & Code of conduct based \\
\hline & Nova Scotia & co & Umbrella & Status + Delivery role & Profession-regulators based \\
\hline \multicolumn{2}{|c|}{ Finland } & co & Umbrella & Status + Delivery role & Healthcare-system based \\
\hline \multicolumn{2}{|c|}{ France } & co & Umbrella & Status + Delivery role & Healthcare-system based \\
\hline \multicolumn{2}{|c|}{ Germany } & quasi & $\begin{array}{l}\text { Profession } \\
\text { specific }\end{array}$ & Status + Delivery role & $\begin{array}{c}\text { IPE based } \\
\text { co }\end{array}$ \\
\hline \multicolumn{2}{|c|}{ New Zealand } & Umbrella & Status + & Delivery role & Profession-regulators based \\
\hline \multicolumn{2}{|c|}{ Switzerland } & co & $\begin{array}{l}\text { Profession } \\
\text { specific }\end{array}$ & Status + Delivery role & $\begin{array}{c}\text { IPE based } \\
\text { co }\end{array}$ \\
\hline \multicolumn{2}{|c|}{ United Kingdom } & Umbrella & Status + & Delivery role & IPE based \\
\hline \multicolumn{2}{|c|}{ United State of America } & quasi & $\begin{array}{l}\text { Profession } \\
\text { specific }\end{array}$ & Status + Delivery role & IPE based \\
\hline
\end{tabular}

\section{A common error and a common perspective}

First, most social science studies-and even some doctrinal articles-recognized the importance of professional regulation as a key factor of IPC, task reallocation, or cross-boundary work $[6,16,17,18,19,20]$. Those studies are, however, bearers of a common misconception about the nature of healthcare's legal framework and professional regulation $[2,6,21,22]$. The peculiar aspect of law is its specificity to a jurisdiction, which is not necessarily determined by a country's geographic frontiers. It is then important to pay attention to those jurisdictions. From a legal perspective, it is incorrect to say there is one Canadian healthcare system, one Swiss healthcare system, or one American healthcare system, since their legal bases are provincial (Canada), cantonal (Switzerland), or state-based (America) and can vary [22,23]. These systems are plural and mandate a jurisdiction-specific approach. When it comes to the legal competence structure of healthcare, Québec, for example, is actually as different from British Columbia or Nova Scotia as Australia is from New Zealand. To study those systems as one entity across one country would give the 
5

IPC and Law: Analysis

Girard researcher or the policymaker a picture that is neither clear nor exact, and one that could lead to inefficient policy changes [9].

Exploring all 14 areas through the lens of jurisdiction specificity revealed a general tendency for robust regulations specific to healthcare or health professions in each place. They were either specific regulations about specific professions (Québec's Medical Act [24], Québec's Nurses Act [25], Ontario's Medicine Act [26]), global acts about healthcare (Finland's Health Care Act [27], British Columbia's Health Act [28], New South Wales's Health Services 1997 [29]), or global acts about professional practice (Québec's Professional Code [30], Ontario's Regulated Health Profession Act [31], New Zealand's Health Practitioners Competence Assurance Act 2003 [32]). There are two dimensions to health regulation: the regulation of the professional title and the regulation of the healthcare delivery role. All jurisdictions studied had acts, statutes, or regulations monitoring both. In every jurisdiction, the inherent structure of these legal texts favours a mono-professional approach, which is congruent with the literature $[1,3,6,8,33,34]$. From both a legal and an organizational perspective, this leads more toward supervision and deference than collaboration without hierarchy $[35,36,37]$.

\section{A difference in approach: Regulation type}

After exploring what unites these jurisdictions, it is key to explore their differences (see Figure 2). In terms of professional regulation, it is important to first describe the philosophical approach behind professional regulation. Professional regulations can be classified into different categories on a spectrum determined by the participation levels of government and of professional authorities in the regulatory field [38]. An area where the government participates the least is called "quasi-regulation"; it is represented by two jurisdictions in this study: the United States of America and Germany. These jurisdictions are not free of regulation, but the central government is less actively involved in specific regulation, leading to both rigid professional boundaries and the potential for innovation at the same time $[16,17,39,40]$. In Germany, for example, the Federal Joint Committee is a legal entity outside of the Ministry of Health itself and it has the mandate to regulate healthcare (based on Germany's Social Code, Book Five [41]). At the other end of the spectrum, explicit

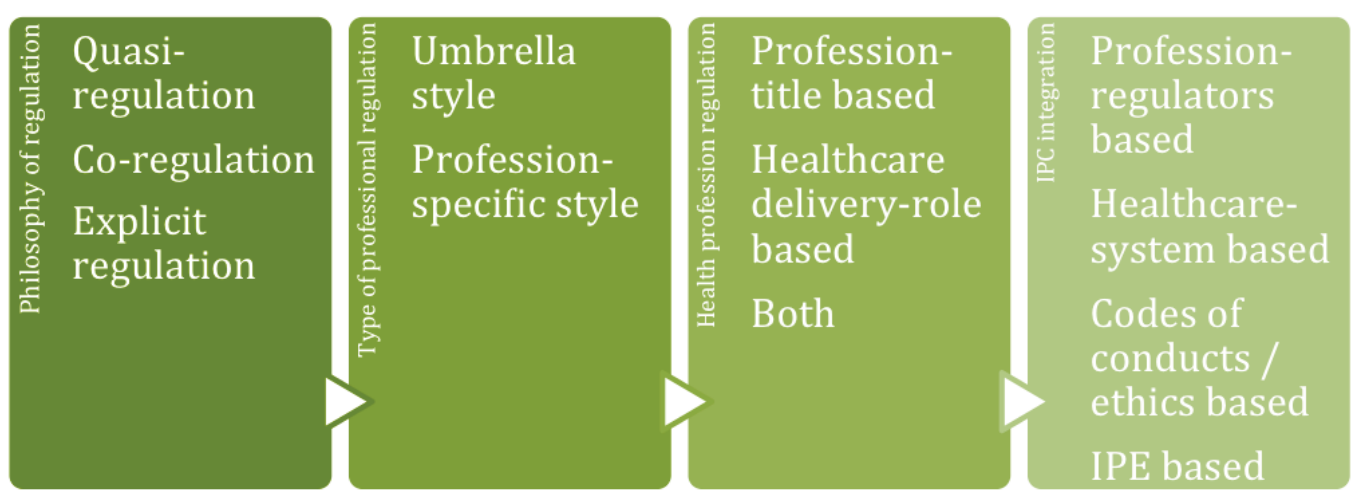

Figure 2: A conceptual analysis of IPC's legal framing 
6

IPC and Law: Analysis

Girard

Journal of Research in Interprofessional Practice and Education

Vol. 9.2

2019 regulation has the least participation of professional authorities, and only one country in the study fits such a profile: Belgium. Interestingly, it is the jurisdiction in Europe where nursing autonomy and IPC was "high" [42].

Between those two extremes is co-regulation, where there is shared ownership of the regulatory field between the government and the professional organization. It is the most common type of regulation found in this study, used by 11 of 14 jurisdictions. Co-regulation can take many forms. It can be closer to explicit regulation, with more institutional control of professional structure and practice, as in the United Kingdom with the Profession Authority Standard (as stipulated by Schedule 7 National Health Service Reform and Health Care Professions Act [43]). Or it can be closer to quasi-regulation, with greater autonomy by professional authorities, as in Québec, where professional authorities have the power to issue regulations (as stipulated by Quebec's Professional Code [30]), or Australia with the Australian Health Practitioner Regulation Authorities (AHPRA) (as stipulated in New South Wales' and Victoria's Health Practitioner Regulation National Law $[44,45]$ ).

\section{A difference in approach: Umbrella laws}

Once the importance of regulation is determined, the importance of jurisdiction specificities established, and the types of regulation philosophy introduced, the next step is looking at what is promoted as a legal structure for IPC (see Figure 2). In the legal literature, one type of regulation is recognized as a more flexible legal environment that can ease the implementation of IPC: the umbrella law $[6,10,21,22]$. As its name indicates, an umbrella law is meant to cover most healthcare professions under one single text and can be a solution to turf wars and professional siloesboth elements hindering IPC [3,16,21,35,46-48].

Most jurisdictions (11 of 14) have a type of umbrella law (either specific to healthcare or not) (Québec's Professional Code [30], Ontario's Regulated Health Professions Act [31], Nova Scotia's Regulated Health Professions Network Act [49], British Columbia's Health Professions Act [50], France's Code de Santé Publique Part IV [51], Belgium's Loi coordonnée relative à l'exercice des professions des soins de santé [52], New South Wales,' and the State of Victoria's Health Practitioner Regulation National Law [44,45], New Zealand's Health Practitioners Competence Assurance Act [32]) with the notable exception of the United States of America, Switzerland, and Germany. It does not mean that these jurisdictions have no laws or regulations specific to a given profession, but there is a predominance of the umbrella law in the profession regulation structures, giving rise to a common structure in either care institutions, the professions, or both $[2,23,40]$. Since, according to legal specialists, all these texts overlap in different ways to include multiple professions, they work by creating a common safe legal space to anchor IPC $[6,21,22]$.

\section{The presence of IPC in legal texts}

A search for clear references to IPC was then conducted in the legal texts (see Figure 2). Only half of the states and countries studied (7 of 14) integrate collaboration in their main legal structure. These regulation attempts vary both in context and in linguistic form and can be divided into two-not necessarily mutually exclu- 
7

IPC and Law: Analysis

Girard

Journal of Research in Interprofessional Practice and Education

Vol. 9.2

2019 sive-categories: those that choose to regulate professional individuals doing IPC and those that choose to regulate the interprofessional healthcare system structure.

The first group, the "professional regulator avenue," is quite diverse. For example, in 2018 New Zealand added a paragraph to the Health Practitioners Competence Assurance Act 2003 called "Functions of Authorities." The act now states that professional authorities have a duty "to promote and facilitate interdisciplinary collaboration and cooperation in the delivery of health services." (Part $6 \mathrm{~s}$ 118) [32] Ontario chose the same approach in its Regulated Health Professions Act, integrating collaboration in the subsection "Objects of College" (article 3 al.1, 4.1e and 3 al. 1, 9e of Schedule 2) [31]. The approach in Nova Scotia is quite similar, but a bit more robust. In 2012, lawmakers chose to issue specific statute, the Regulated Health Professions Network Act [49], to put forward IPC at all levels of professional regulation and practice. As in New Zealand and Ontario, this text primarily promotes a top-down approach to IPC implementation, with the advantage of being specifically constructed for IPC. British Columbia chose a slightly different approach with a multilevel obligation. First, the minister has the right to refer to an advisory panel to resolve interjurisdictional or collaborative practice issues (article 6 al.3 1a) [50]. Second, this statute includes a duty for colleges to both "promote and enhance" collaboration and IPC (article 16 al.2k) [50].

The second group embeds IPC in the actual healthcare structure and is as diverse as the first group. For example, Finland's lawmakers include IPC in the definition of a primary care unit in its Health Care Act[27], both in the objective of the actwhich states that its goal is to "improve the operating conditions of primary healthcare and strengthen cooperation between healthcare providers" (section 2, a.5)[27] — and in outlining that primary healthcare units should "employ healthcare professionals with multidisciplinary competence and supports the planning of healthcare provision" (section 2, a.35) [27]. Contrary to the Finland global structure approach, Belgium anchored IPC in a specific treatment structure, in addition to the recurrent IPC duty included in the professional practice section of its statute (article 28 , article 45 al.b/ii and article 68 al.2/1) [52].

The remainder can be separated into two groups. Three integrate IPC at the level of professional regulation (Québec and both Australian states), either in codes of conducts or in specific regulatory body directives for professionals. The four remaining countries (the U.S., Switzerland, the U.K., and Germany) have structured interprofessional education (IPE) only, regulated or not, with no clear legal initiatives found in the relevant legal texts. This choice is not clearly linked with weaker IPC but tends to promote a more "pilot-project" approach, limiting stability [19,39,53,54].

\section{Discussion}

Law is ubiquitous in professional practice. However, it is not always well understood or studied in the context of IPC. This descriptive presentation focused on 14 different jurisdictions, including countries, provinces, and states. Half the jurisdictions are truly trying to regulate IPC by introducing a clear notion in acts and statutes, showing a strong desire on behalf of lawmakers to solidify IPC implementation. 
8

IPC and Law: Analysis

Girard

Journal of Research in Interprofessional Practice and Education

Vol. 9.2

2019
Incorporating IPC through a formal legal structure can be a sign that policymakers are more and more aware of the importance of regulation as a potential limiting factor for the implementation of IPC-as social science literature has strongly suggested for many years $[1,55,56]$. A replication study in five to 10 years would be necessary to clarify the relationship between the strength of IPC and its legal presence.

Even though collaboration is starting to be incorporated into regulation, there seems to be a lack of research on what works in regulation and what fails to promote IPC. This absence might be due to the complexity of an interdisciplinary approach to socio-legal studies. Legal scholars and social science scholars need to collaborate and exchange methods and concepts to correctly apprehend the situation. Although there is little literature specifically on IPC, there is evidence specific to healthcare showing that legal texts offer an incomplete picture of the actual system and individual behaviours $[57,58,59]$. In that context, both the published legal literature and the social science literature are insufficient to inform lawmakers and policymakers on how to efficiently regulate IPC. More publications combining legal and social data, either quantitative or qualitative, are required to explore the subject.

A second explanation for the paucity of research is the nature of the law-practice relationship. Healthcare legal studies are still missing theoretical frameworks to explain how the law actually alters health professionals' behaviour toward IPC. The importance of the umbrella law is only put forward in legal studies. From a social science perspective, there is a lack of data to explain that impact. Other fields reveal that the interaction between a legal text and actual behaviour is far from simple $[60,61,62]$. Law and Society Association scholars produced conceptual models on these relationships, but there is a lack of data regarding IPC specifically, and it is difficult to infer actual changes in professional practice from legal texts [58]. This research could not gather any studies on professionals' perceptions of or knowledge about the legal structure of IPC. The gap needs to be filled.

One can argue that changing some part of the law would be enough to facilitate IPC from a policy standpoint and that the actual body of literature should be sufficient to inform policymakers. A broad perspective on law is essential for policymakers to overcome the anchoring nature of healthcare legal structures. All 14 jurisdictions included in this study showed a strong mono-professional orientation in terms of acts and statutes. This aligns with a study published in 2013 about three Commonwealth countries [2] and with the legal literature $[6,8,17,21]$. That structure is certainly not conducive to IPC, even though there is no written restriction to IPC. Limited knowledge of the nuts and bolts of existing statutes or legal texts will hinder the implementation of IPC. In accordance with concepts presented by the Law and Society Association, individuals, when lacking knowledge, will anchor their behaviours according to their social group's vision and interpretation of the law, their social status, and their own experience of law [57]. In healthcare professional practice, all these factors are linked to the historical care structure. These elements can then create a tendency to interpret newly enacted laws and statutes in accordance with the professional's perception of his or her traditional duties [58,59]. Since most healthcare systems addressed here have a structure rooted earlier than 1990, 
9

IPC and Law:

Analysis

Girard that anchoring is congruent with the medical dominance and practice silos of that time $[3,4,7]$. In that light, in co-regulation or self-regulation structures, there might be a tendency in professional regulating organizations to interpret the law narrowly and to promote that narrow interpretation among their members $[1,17]$. A broader perspective on law and regulation would inform policymakers and allow them to effectively address change in behaviours using the most efficient legal instrument.

This study has several limitations. Only actual legal texts, the so-called law of the books or "hard law," were investigated. Court decisions or other tribunal decisions were not examined and there was no way of testing the actual impact of the texts in the corresponding healthcare system. In addition, there were no studies about the social impact of large-scale regulation in healthcare regarding IPC or professional practice regulation. Also, "soft laws," such as codes of ethics and statements from professional entities, were not incorporated, as only statutes and policies were thought to correspond to a strong expression of professional or social will.

\section{Conclusion}

Although the practice of IPC is recognized as important, the legal structure still has to catch up with this organizational trend. In that regard, regulatory fields in the countries and states studied here showed significant improvements in the last few years, with the creation of umbrella laws, regulation integration, and increased IPC presence in legal texts. Nonetheless, there is a lack of proper research to inform policy development. If the aim of the IPC scientific community is to ensure stable IPC, law and social science scholars need to investigate more deeply how regulation and legal framing affect the enactment of IPC in practice. This would provide evidencebased insights to policymakers in order to guide them in drafting regulations that can have a positive impact on IPC.

\section{Acknowledgement}

The author would like to extend sincere thanks to Cecile Petitgand, Odile Gagnon, Laure Bagliniere, and Frederic Erard for their help in this endeavour.

\section{Websites}

Google Scholar, https://scholar.google.ca/

HeinOnline, https://home.heinonline.org/

PubMed, https://www.ncbi.nlm.nih.gov/pubmed/

\section{References}

1. Bourgeault, I. L., \& Mulvale, G. (2006). Collaborative health care teams in Canada and the USA: Confronting the structural embeddedness of medical dominance. Health Sociology Review, 15(5), 481-495. doi:10.5172/hesr.2006.15.5.481

2. Bourgeault, I. L., \& Grignon, M. (2013). A comparison of the regulation of health professional boundaries across OECD countries. The European Journal of Comparative Economics, 10(2), $199-224$.

Journal of Research in Interprofessional Practice and Education
3. Hall, P. (2005). Interprofessional teamwork: Professional cultures as barriers. Journal of Interprofessional Care, 19(sup1), 188-196. doi:10.1080/13561820500081745

4. Thistlethwaite, J., Jackson, A., \& Moran, M. (2013). Interprofessional collaborative practice: A deconstruction. Journal of Interprofessional Care, 27(1), 50-56. doi:10.3109/13561820.2012 .730075 
10

IPC and Law: Analysis

Girard

5. Abbott, A. (1988). The System of Professions: An Essay on the Division of Expert Labor. Chicago, IL: University of Chicago Press.

6. Lahey, W., \& Currie, R. (2005). Regulatory and medico-legal barriers to interprofessional practice. Journal of Interprofessional Care, 19(sup1), 197-223. doi:10.1080/13561820500083188

7. Ries, N.M. (2017). Law matters: How the legal context in Canada influences interprofessional collaboration. Journal of Interprofessional Care, 31(4), 417-419. doi:10.1080/13561820.2017 .1310495

8. Laverdière, M., \& Régis, C. (2016). Comprendre les conflits interdisciplinaires pour mieux y faire face: un défi pour le système professionnel québécois. In R.P. Kouri, C. Régis, \& L. Khoury (Eds.), Les grands conflits en droit de la santé: les rencontres en droit de la santé, 1, 193-234.

9. Safriet, B. J. (2002). Closing the gap between can and may in health-care providers' scopes of practice: a primer for policymakers. Yale Journal on Regulation, 19, 301.

10. Nelson, S., Turnbull, J., Bainbridge, L., Caulfield, T., Hudon, G., et al. (2014). Optimisation des champs d'exercice: De nouveaux modèles de soins pour un nouveau système de soins de santé (comité d'expert). Académie canadienne des sciences de la santé. URL: http://www.cahs-acss.ca /wp-content/uploads/2014/11/Optimisation-des-champs-d\%23U2019exercice_RAPPORT -French1.pdf [September 24, 2018].

11. Levitsky, S.R. (2013). Integrating law and health policy. Annual Review of Law and Social Science, 9(1), 33-50. doi:10.1146/annurev-lawsocsci-102612-133949

12. Stryker, R. (2012). Mechanisms of legal effect: Perspectives from the Law \& Society Tradition (SSRN Scholarly Paper No. ID 2041527). Rochester, NY: Social Science Research Network. URL: https://papers.ssrn.com/abstract=2041527 [September 24, 2018].

13. Edelman, L.B., Fuller, S.R., \& Mara-Drita, I. (2001). Diversity rhetoric and the managerialization of law. American Journal of Sociology, 106(6), 1589-1641. doi:10.1086/321303

14. Grant, M.J., \& Booth, A. (2009). A typology of reviews: an analysis of 14 review types and associated methodologies. Health Information \& Libraries Journal, 26(2), 91-108. doi:10.1111/j.14711842.2009.00848.x

15. Gough, D., Thomas, J., \& Oliver, S. (2012). Clarifying differences between review designs and methods. Systematic Reviews, 1(1), 28. doi:10.1186/2046-4053-1-28

16. Gavil, A.I., \& Koslov, T.I. (2016). A flexible health care workforce requires a flexible regulatory environment: Promoting health care competition through regulatory reform. Washington Legal Review, 91, 147.

17. Dower, C., Moore, J., \& Langelier, M. (2013). It is time to restructure health professions scope-ofpractice regulations to remove barriers to care. Health Affairs, 32(11), 1971-1976. doi:10.1377/hlthaff.2013.0537

18. Regan, S., Orchard, C., Khalili, H., Brunton, L., \& Leslie, K. (2015). Legislating interprofessional collaboration: A policy analysis of health professions regulatory legislation in Ontario, Canada. Journal of Interprofessional Care, 29(4), 359-364. doi:10.3109/13561820.2014.1002907

19. Butcher, D.L., MacKinnon, K., \& Bruce, A.W. (2018). Producing flexible nurses: How institutional texts organize nurses' experiences of learning to work on redesigned nursing teams (Préparer des infirmières polyvalentes : comment des documents officiels orientent les expériences d'apprentissage des infirmières en fonction du travail au sein d'équipes reconfigurées). Quality Advancement in Nursing Education - Avancées en formation infirmière, 4(1). doi:10.17483 /2368-6669.1132

20. Niezen, M.G.H., \& Mathijssen, J.J.P. (2014). Reframing professional boundaries in healthcare: A systematic review of facilitators and barriers to task reallocation from the domain of medicine to the nursing domain. Health Policy, 117(2), 151-169. doi:10.1016/j.healthpol.2014.04.016

21. Ries, N.M. (2016). Innovation in healthcare, innovation in law: Does the law support interprofessional collaboration in Canadian health systems? Osgoode Hall Law Journal, 54(1), 97-124.

22. Lahey, W., \& Fierlbeck, K. (2016). Legislating collaborative self-regulation in Canada: A comparative policy analysis. Journal of Interprofessional Care, 30(2), 211-216. doi:10.3109/13561820 .2015 .1109501

23. Lahey, W. (2013). Legislating interprofessional regulatory collaboration in Nova Scotia. Health Reform Observer - Observatoire des Réformes de Santé, 1(1). doi:10.13162/hro-ors.01.01.04

Journal of Research in Interprofessional Practice and Education

Vol. 9.2

2019
24. Government of Québec. Medical Act, CQLR c M-9. URL: http://legisquebec.gouv.qc.ca/en/Show Doc/cs/M-9 [September 20, 2018].

25. Government of Québec. Nurses Act, CQLR c I-8. URL: http://legisquebec.gouv.qc.ca/en/Show Doc/cs/I-8 [September 25, 2018].

26. Government of Ontario. Medicine Act, Pub. L. No. SO 1991, c 30. URL: https://www .canlii.org/en/on/laws/stat/so-1991-c-30/latest/so-1991-c-30.html [September 25, 2018]. 
11

IPC and Law: Analysis

Girard

Journal of Research in Interprofessional Practice and Education

Vol. 9.2

2019
27. Ministry of Social Affairs and Health, Finland. Health Care Act, Pub. L. No. No. 1326/2010.

28. Government of British Columbia. Health Act, Pub. L. No. [RSBC 1979] c. 161.

29. New South Wales Government. Health Services Act 1997, Pub. L. No. 1997 No 154. URL: https://www.legislation.nsw.gov.au/\#/view/act/1997/154 [September 20, 2018].

30. Government of Québec. Professional Code, CQLR c C-26. URL: http://legisquebec.gouv.qc.ca/en /ShowDoc/cs/C-26 [September 20, 2018].

31. Government of Ontario. Regulated Health Professions Act, 1991, Pub. L. No. S.O. 1991, CHAPTER 18. URL: https://www.ontario.ca/laws/statute/91r18 [September 20, 2018].

32. New Zealand Government. Health Practitioners Competence Assurance Act 2003, Pub. L. No. 2003 No 48. URL: http://www.legislation.govt.nz/act/public/2003/0048/latest/DLM203312.html [September 20, 2018].

33. Masterson, A. (2002). Cross-boundary working: a macro-political analysis of the impact on professional roles. Journal of Clinical Nursing, 11(3), 331-339.

34. Saks, M. (2012). The dilemmas of inter-professionalism in health and social care: The role of professions in collaborative working. Niigata journal of health and welfare, 12(1), 25-28.

35. Fisch, D.M. (2012). Baby steps: The changing relationship between Michigan obstetricians and certified professional midwives. Marquette Elder's Adviser, 14, 87.

36. Crocket, K., Cahill, F., Flanagan, P., Franklin, J., McGill, R., Stewart, A., \& Mulcahy, D. (2009). Possibilities and limits of cross-disciplinary supervision. New Zealand Journal of Counselling, 29(2), 25-43.

37. Williams, J. (2013). From health care to population health: retooling legal structures for a new paradigm. Journal of Medical Regulation, 99(4), 27-37.

38. Australian Health Practitioner Regulation Agency. (2016, November). Comparison of international accreditation systems for registered health professions. AHPRA. URL: https://www .ahpra.gov.au/publications/accreditation-publications.aspx [September 23, 2018].

39. Smith, D.C. (2016). Interprofessional collaboration in perinatal care. The Journal of Perinatal \& Neonatal Nursing, 30(3), 167-173.

40. Cameron, A. (2011). Impermeable boundaries? Developments in professional and inter-professional practice. Journal of Interprofessional Care, 25(1), 53-58.

41. German Federal government. (1998). Sozialgesetzbuch (SGB) Fünftes Buch (V). , Pub. L. No. BGBl. I p. 2477. URL: http://www.gesetze-im-internet.de/sgb_5/ [September 20, 2018].

42. Schönfelder, W., \& Nilsen, E. A. (2016). An ideal-typical model for comparing interprofessional relations and skill mix in health care. BMC Health Services Research, 16(1), 633. doi:10.1186 /s12913-016-1881-9

43. United Kingdom Government. (2002). SCHEDULE 7 - The Professional Standards Authority for Health and Social Care - National Health Service Reform and Health Care Professions Act 2002, Pub. L. No. 2002 c. 17. URL: http://www.legislation.gov.uk/ukpga/2002/17/schedule/7 [September 25, 2018].

44. New South Wales Government. (2009). Health Practitioner Regulation National Law (NSW). , Pub. L. No. 2009 No 86a. [September 20, 2018].

45. State of Victoria Government. (2009). Health Practitioner Regulation National Law (Victoria) Act 2009, Pub. L. No. 79. [September 23, 2018].

46. Bertness, J.A. (2009). Rhode island nurse practitioners: are they legally practicing medicine without a license. Roger Williams University Law Review, 14, 215.

47. Gerardi, D. (2007). The emerging culture of health care: Improving end-of-life care through collaboration and conflict engagement among health care professionals. Ohio State Journal on Dispute Resolution, 23, 105.

48. Beckett, K., \& Hoffman, B. (2005). Challenging medicine: Law, resistance, and the cultural politics of childbirth. Law \& Society Review, 39(1), 125-170. doi:10.1111/j.0023-9216.2005.00079.x

49. Nova Scotia Government. Regulated Health Professions Network Act. , Pub. L. No. 2012 c. 48.

50. Government of British Columbia. Health Professions Act. , Pub. L. No. RSBC 1996 c. 183.

51. Code de Santé Publique: Quatrième partie : Professions de santé. , Code de Santé Publique $\$$ L40011 à L4444-3. Paris, France. URL: https://www.legifrance.gouv.fr/affichCode.do?idArticle $=$ LEGIARTI000033896634\&idSectionTA=LEGISCTA000033894616\&cidTexte $=$ LEGIT EXT000006072665\&dateTexte=20190726 [September 26, 2018].

52. Belgique \& Chancellerie du Premier Ministre. (2015). Loi coordonnée relative à l'exercice des professions des soins de santé. , Pub. L. No. 2015A24141.

53. Barker, K.K., Bosco, C., \& Oandasan, I.F. (2005). Factors in implementing interprofessional education and collaborative practice initiatives: Findings from key informant interviews. Journal of Interprofessional Care, 19(sup1), 166-176. doi:10.1080/13561820500082974 
12

IPC and Law: Analysis

Girard
54. Careau, E., Biba, G., Brander, R., Van Dijk, J. P., Verma, S., Paterson, M., \& Tassone, M. (2014). Health leadership education programs, best practices, and impact on learners; knowledge, skills, attitudes, and behaviors and system change: a literature review. Journal of Healthcare Leadership, 39-50. doi:10.2147/JHL.S61127

55. San Martín-Rodríguez, L., Beaulieu, M.-D., D’Amour, D., \& Ferrada-Videla, M. (2005). The determinants of successful collaboration: A review of theoretical and empirical studies. Journal of Interprofessional Care, 19(sup1), 132-147. doi:10.1080/13561820500082677

56. Sicotte, C., D'Amour, D., \& Moreault, M.-P. (2002). Interdisciplinary collaboration within Québec community health care centres. Social Science \& Medicine, 55(6), 991-1003. doi: $10.1016 /$ S0277-9536(01)00232-5

57. Silbey, S.S. (2005). After legal conciousness. Annual Review of Law and Social Science, 1(1), 323-368. doi:10.1146/annurev.lawsocsci.1.041604.115938

58. Kellogg, K.C. (2011). Challenging operations: Medical reform and resistance in surgery. Chicago, IL: University of Chicago Press.

59. Heimer, C.A. (1999). Competing institutions: Law, medicine, and family in neonatal intensive care. Law \& Society Review, 33(1), 17-66. doi:10.2307/3115095

60. Tyler, T.R. (2013). Why people cooperate: the role of social motivations. Princeton, NJ: Princeton University Press.

61. Tyler, T.R. (2006). Why people obey the law. Princeton, NJ: Princeton University Press.

62. Thaler, R.H., \& Sunstein, C.R. (2009). Nudge: improving decisions about health, wealth, and happiness (Rev. and expanded ed.). New York, NY: Penguin Books. 